\title{
Open
}

\section{Selenium status during pregnancy and child psychomotor development-Polish Mother and Child Cohort study}

\author{
Kinga Polanska', Anna Krol', Wojciech Sobala', Jolanta Gromadzinska², Renata Brodzka², Gemma Calamandrei , \\ Flavia Chiarotti ${ }^{3}$, Wojciech Wasowicz ${ }^{2}$ and Wojciech Hanke ${ }^{1}$
}

BACKGROUND: The studies on the impact of selenium (Se) levels in different pregnancy periods on child psychomotor functions are limited. The aim of this study was to evaluate the impact of prenatal Se on child neurodevelopment.

METHODS: The study population consisted of 410 motherchild pairs from Polish Mother and Child Cohort. Se levels were measured in each trimester of pregnancy, at delivery, and in cord blood by graphite furnace atomic absorption spectrometry. Psychomotor development was assessed in children at the age of 1 and 2 y using the Bayley Scales of Infant and Toddler Development.

RESULTS: Plasma Se levels decreased through pregnancy (from $48.3 \pm 10.6 \mu \mathrm{g} / \mathrm{l}$ in the first trimester to $38.4 \pm 11.8 \mu \mathrm{g} / \mathrm{l}$ at delivery; $P<0.05)$. A statistically significant positive association between Se levels in the first trimester of pregnancy and motor development ( $\beta=0.2, P=0.002)$ at 1 y of age, and language development $(\beta=0.2, P=0.03)$ at 2 y of age was observed. The positive effect of Se levels on cognitive score at $2 y$ of age was of borderline significance $(\beta=0.2, P=0.05)$.

CONCLUSION: Prenatal selenium status was associated with child psychomotor abilities within the first years of life. Further epidemiological and preclinical studies are needed to confirm the association and elucidate the underlying mechanisms of these effects.

$\mathrm{t}$ is widely acknowledged that maternal nutrient status can influence development of fetal brain and consequently maturation of the child's cognitive functions, psychomotor abilities, intelligence, and behavior (1). In this framework, micronutrient supplementation that it is widely recommended during pregnancy period may have a significant impact on child neurodevelopment.

Selenium (Se) is involved in biosynthesis of several selenoproteins. It is particularly well maintained in the brain, even in the presence of a lower dietary supply (2). This suggests a relevant role of Se in the brain, as an essential component of a number of enzymes including glutathione peroxidases and thioredoxin reductases. They act as antioxidants by catalyzing breakdown of hydrogen peroxide and organic hydroperoxides or forming reduced protein disulfide bonds $(3,4)$. Se is also incorporated into deiodinases, which are responsible for conversion of the thyroid hormone thyroxine (T4) to its active form, triiodothyronine (T3).

On average, Se intake of 60-70 $\mu$ g per day is recommended for adults, with increasing requirements for pregnant and lactating women (5). Se worldwide dietary intake is high in some countries, like Venezuela, Canada, the United States, and Japan, and much lower in Europe (2). The nationally representative dietary survey data from eight European countries has highlighted that there is a risk of low intake of essential trace elements in specific populations and age groups (6). Based on such estimates, the mean Se intake in women aged 18-60 ranged from $34 \mu \mathrm{g} / \mathrm{d}$ in Denmark, to $45 \mu \mathrm{g} / \mathrm{d}$ in France. Further analysis has indicated that from 36 to $76 \%$ of women had Se intake below the lower reference nutrient intake, namely, the intake value below which it is unlikely that normal health can be maintained over longer periods.

The existing studies evaluating the impact of food and micronutrients supplementation on children's development have produced conflicting results, mainly because of the lack of a valid indicator and assessment of the micronutrients and outcome variables (7-9). Although there is some evidence to support multi micronutrients having positive effect on child psychomotor development, the data for single nutrients is much weaker (7). In animal models, Se deficiency has been shown to affect neurological development in the offspring $(3,10,11)$. Two recently published studies have evaluated the impact of Se on child development $(12,13)$. The first one has indicated that both low and high levels of cord serum Se had adverse effects on an infant's neurobehavioral development (12). The second study by Skröder et al. (13) indicated a positive effect of maternal selenium status during pregnancy on children's development at $1.5 \mathrm{y}$ of age.

The aim of this study was to evaluate the impact of Se during pregnancy period on child psychomotor development based

'Department of Environmental Epidemiology, Nofer Institute of Occupational Medicine, Lodz, Poland; ${ }^{2}$ Department of Biological and Environmental Monitoring, Nofer Institute of Occupational Medicine, Lodz, Poland; ${ }^{3}$ Unit of Neurotoxicology and Neuroendocrinology, Department of Cell Biology and Neuroscience, Istituto Superiore di Sanità, Rome, Italy. Correspondence: Kinga Polanska (kinga@imp.lodz.pl)

Received 1 October 2015; accepted 13 December 2015; advance online publication 23 March 2016. doi:10.1038/pr.2016.32 


\section{Articles | Polanska et al.}

on the prospective Polish Mother and Child Cohort (REPRO_ PL) study (14).

\section{RESULTS}

\section{Parental and Child Characteristics}

Parental and child characteristics are summarized in Table 1. About $52 \%$ of the children were girls. On average, the children were born at the 39th wk of gestation $( \pm 1.3 \mathrm{wk})$ with the mean birth weight of $3,359 \mathrm{~g}( \pm 484 \mathrm{~g})$. The mean maternal age was 31 $( \pm 4.4 \mathrm{y})$ and paternal $33( \pm 5.5 \mathrm{y})$. Most of the mothers $(66 \%)$ and $43 \%$ of the fathers had a university degree. The majority of women were married (76\%) and employed (89\%). About $9 \%$ of the women indicated alcohol consumption and 11\% were classified as smokers based on the cotinine level in saliva. In addition, half of the children were exposed to environmental tobacco smoke (ETS) within the first $2 \mathrm{y}$ of life. Less than $17 \%$ of the women consumed multiple micronutrient capsules (with maximum $55 \mu \mathrm{g}$ Se content) during the first trimester of pregnancy (22\% during the second and 20\% during the third trimester). The mean composite scores for cognitive, language, and motor development were on an average or high average level in the assessments carried out at 1 and $2 \mathrm{y}$ of age (Table 2).

\section{Selenium Level During Pregnancy}

Se levels in the blood collected in each trimester of pregnancy, at delivery and in cord blood, are presented in Table 2, while correlations between microelement levels in each time period are shown in Table 3. The mean Se level decreased through pregnancy period and at delivery (from $48.3 \pm 10.6 \mu \mathrm{g} / \mathrm{l}$ in the first trimester to $38.4 \pm 11.8 \mu \mathrm{g} / \mathrm{l}$ at delivery) $(P<0.05)$. A moderate correlation was observed between Se levels in blood collected in the first and the second and between the first and the third trimester of pregnancy $(r=0.4)$ as well as between the second and the third trimester of pregnancy, and between the third trimester of pregnancy and delivery $(r=$ $0.5)$. The weakest correlation was observed between Se levels in the three trimesters of pregnancy and cord blood (the lowest between Se levels in the second trimester and cord blood $r=$ $0.08)$. The correlation between Se level in maternal blood collected at delivery and in cord blood was 0.4.

\section{Association Between Se Level During Pregnancy and Child Psychomotor Development}

Table 4 presents the association between maternal Se levels in the first trimester of pregnancy, at delivery, and in cord blood and child neurodevelopment. In the model adjusted for the examiner, a statistically significant positive association was observed between Se levels in the blood collected during the first trimester of pregnancy and child motor skills at $1(\beta=$ $0.2, P=0.001)$ as well as $2(\beta=0.2 ; P=0.04)$ y of age, and cognitive development at 2 y of age $(\beta=0.2 ; P=0.03)$. For language abilities at $2 \mathrm{y}$ of age, the association was of borderline significance $(\beta=0.2, P=0.05)$. In the same model for Se levels in the blood collected from the mothers at delivery, no statistically significant associations with any domains of child neurodevelopment were observed $(P>0.05)$, whereas for Se levels in cord blood, a statistically significant positive association was observed in the case of language development at $2 \mathrm{y}$ of age $(\beta=0.3, P=0.02)$. The analysis with adjustment for a variety of confounders confirmed a statistically significant positive association between Se levels in blood collected in the first trimester of pregnancy and motor functions at $1(\beta=0.2$, $P=0.002)$ and language functions at $2 \mathrm{y}$ of age $(\beta=0.2, P=$ $0.03)$. For cognitive abilities at $2 y$ of age, the association was of borderline significance $(\beta=0.2, P=0.05)$.

\section{DISCUSSION}

This prospective Polish Mother and Child Cohort indicated a positive effect of prenatal selenium status on child psychomotor abilities within the first $2 \mathrm{y}$ of life. It needs to be pointed out that significant effects of Se on child development were mainly found when considering Se level in the first trimester of pregnancy; nevertheless, data concerning the effect of Se levels at delivery and in cord blood suggest a similar magnitude of the association, although not statistically significant taking into account the power limitations for that associations.

Two recently published studies have evaluated the impact of Se levels on child neurodevelopment $(12,13)$. In the study by Skröder et al. (13), the Bayley Scales of Infant Development and MacArthur's Communicative Development Inventory were used for child psychomotor assessment at $1.5 \mathrm{y}$ of age. In this study, similarly to our findings, increase in maternal Se concentration was associated with improvement in children's language and psychomotor development (13). The second study has indicated that both low and high levels of cord serum Se had adverse effects on neonatal neurodevelopment (12). In our assessment, maximum Se level in cord plasma was $56 \mu \mathrm{g} / \mathrm{l}$, which is much lower than observed in previous study, so the analysis for a high Se level had no point.

Our findings support the experimental evidence indicating a significant role of Se in brain and behavior development. Marked reduction of brain Se content following genetic inactivation of selenoprotein $\mathrm{P}$ produces movement disorders and spontaneous seizures in mice $(15,16)$. Although the mechanisms by which Se influences neurodevelopment are still to be elucidated, animal studies reported a protective role of Se against cerebral ischemia-induced neuronal damage $(17,18)$ and $\mathrm{MeHg}$ behavioral toxicity (19). In agreement, in vitro studies have shown that Se protects neurons from oxidative damage and inflammatory processes $(20,21)$. In addition, the role of Se in activation of thyroid hormones reported by animal studies might also be implicated in Se effects on maturation of cognitive functions (22). Of note, Se is also able to counteract the adverse developmental effects of lead, as indicated by a recent rat study showing amelioration of lead-induced cognitive deficits in adult rats supplemented with Se (23). Thus, Se deficiency could have more impact in the presence of adverse environmental factors (including lead exposure), to which the fetus and infant could be exposed to in real scenarios.

Based on the existing data, the intake of Se varies hugely worldwide from low to even toxic concentrations with the mean values of $40 \mu \mathrm{g}$ per day in Europe, and $93 \mu \mathrm{g}$ per day in 
Table 1. Children and parental characteristics $(N=410)$

\begin{tabular}{|c|c|c|}
\hline Characteristic & $n$ or mean & $\%$ or SD \\
\hline \multicolumn{3}{|l|}{ Gender $(N=410)$} \\
\hline Girls & 211 & 51.5 \\
\hline Birth weight $(\mathrm{g})$; mean, SD $(N=396)$ & $3,358.7$ & 484.3 \\
\hline Birth length $(\mathrm{cm})$; mean, SD $(N=396)$ & 55.1 & 3.5 \\
\hline Head circumference at birth $(\mathrm{cm})$; mean, SD $(N=340)$ & 34.3 & 1.6 \\
\hline \multicolumn{3}{|l|}{ Breastfeeding (months) $(N=409)$} \\
\hline $0-5$ & 179 & 43.8 \\
\hline$\geq 6$ & 230 & 56.2 \\
\hline \multicolumn{3}{|l|}{ Day care attendance at 1 y olds $(N=393)$} \\
\hline No & 367 & 93.4 \\
\hline Yes & 26 & 6.6 \\
\hline \multicolumn{3}{|l|}{ Age at Bayley-III test administration (months) } \\
\hline For 1 y olds; mean, SD $(N=374)$ & 12.8 & 1.5 \\
\hline For 2 y olds; mean, SD $(N=234)$ & 24.9 & 2.8 \\
\hline \multicolumn{3}{|l|}{ Type of delivery $(N=375)$} \\
\hline Cesarean & 138 & 36.8 \\
\hline Vaginal & 237 & 63.2 \\
\hline Maternal age (years); mean, SD ( $N=389)$ & 30.8 & 4.4 \\
\hline Paternal age (years); mean, SD $(N=385)$ & 32.7 & 5.5 \\
\hline \multicolumn{3}{|l|}{ Maternal education $(N=410)$} \\
\hline Primary/vocational & 22 & 5.4 \\
\hline Secondary & 118 & 28.8 \\
\hline Unmarried & 97 & 23.7 \\
\hline \multicolumn{3}{|l|}{ Maternal employment $(N=409)$} \\
\hline Employed & 362 & 88.5 \\
\hline Unemployed & 47 & 11.5 \\
\hline \multicolumn{3}{|l|}{ Socioeconomic status $(N=405)$} \\
\hline High & 91 & 22.5 \\
\hline Medium & 274 & 67.7 \\
\hline Low & 40 & 9.9 \\
\hline Maternal prepregnancy BMI $\left(\mathrm{kg} / \mathrm{m}^{2}\right)$; mean, SD $(N=406)$ & 22.6 & 3.7 \\
\hline \multicolumn{3}{|c|}{ Multiple micronutrient supplementation during the first trimester (including $\mathrm{Se}$ ) $(\mathrm{N}=410)$} \\
\hline Yes & 69 & 16.8 \\
\hline No & 341 & 83.2 \\
\hline \multicolumn{3}{|l|}{ Saliva cotinine level in pregnancy $(N=369)$} \\
\hline$<10 \mathrm{ng} / \mathrm{ml}$ & 327 & 88.6 \\
\hline$\geq 10 \mathrm{ng} / \mathrm{ml}$ & 42 & 11.4 \\
\hline \multicolumn{3}{|l|}{ Alcohol consumption during pregnancy $(N=358)$} \\
\hline No & 327 & 91.3 \\
\hline Yes & 31 & 8.7 \\
\hline \multicolumn{3}{|l|}{ Children's ETS exposure after birth $(\mathrm{N}=410)$} \\
\hline No & 200 & 48.8 \\
\hline Yes & 210 & 51.2 \\
\hline
\end{tabular}

ETS, environmental tobacco smoke. 


\section{Articles | Polanska e tal.}

the United States (2). The recently published study performed in Poland indicates the mean daily intake of Se at the level of $30 \mu \mathrm{g} / \mathrm{d}$ (24). Taking into account plasma Se levels below $60 \mu \mathrm{g} / \mathrm{l}$ as low $(25,26), 92 \%$ of our studied women seemed to have inadequate Se status in early pregnancy (Se levels below $50 \mu \mathrm{g} / \mathrm{l}$ were observed in $76 \%$ of our pregnant women). Se levels observed in our population were lower comparing to other studies in this field $(48.3 \mu \mathrm{g} / \mathrm{l}$ plasma Se level between 8 and 12 wk of pregnancy for REPRO_PL cohort vs. $60 \mu \mathrm{g} / 1$ median plasma Se at $14 \mathrm{wk}$ of pregnancy in Bangladesh (13) or $31 \mu \mathrm{g} / \mathrm{l}$ Se level in cord plasma for REPRO_PL cohort vs. 125 $\mu \mathrm{g} / \mathrm{l}$ median Se level in Iran (27), $69 \mu \mathrm{g} / \mathrm{l}$ median Se level in Baltimore, USA (28), $63 \mu \mathrm{g} / \mathrm{l}$ in Shanghai, China (12)). Plasma glutathione peroxidase activity correlates with Se in plasma and reaches plateau at plasma concentrations of 70-90 $\mu \mathrm{g} / 1$ (26), which indicates that the women in our study might have a lower activity of this enzyme (only 12 women in REPRO_PL had Se level higher than $70 \mu \mathrm{g} / \mathrm{l})$. It is worth noting that in Poland plasma Se levels have been decreasing in the last three decades $(24,29)$. Cord plasma Se levels in the study performed

Table 2. Characteristics of the exposure and outcome variables

\begin{tabular}{lcccc}
\hline Variables & Mean & SD & Min & Max \\
\hline $\begin{array}{l}\text { Se levels }(\mu \mathrm{g} / \mathrm{l}) \\
\quad \text { in the first trimester of } \\
\text { pregnancy }(N=410)\end{array}$ & 48.3 & 10.6 & 16.1 & 91.4 \\
$\begin{array}{l}\text { in the second trimester of } \\
\text { pregnancy }(N=151)\end{array}$ & 42.3 & 9.1 & 14.8 & 69.7 \\
$\begin{array}{l}\text { in the third trimester of } \\
\text { pregnancy }(N=130)\end{array}$ & 37.3 & 9.8 & 14.2 & 61.7 \\
$\begin{array}{l}\text { in maternal blood at } \\
\text { delivery }(N=310)\end{array}$ & 38.4 & 11.8 & 13.8 & 86.3 \\
$\begin{array}{l}\text { in cord blood }(N=311) \\
\text { Composite score for one year old children } N=374\end{array}$ & 31.1 & 8.2 & 13.8 & 56.3 \\
$\begin{array}{l}\text { Cognitive } \\
\text { Language }\end{array}$ & 106.8 & 10.3 & 80.0 & 145.0 \\
$\begin{array}{l}\text { Motor } \\
\text { Composite score for two years old children }\end{array}$ & 108.4 & 13.6 & 68.0 & 141.0 \\
$\quad \begin{array}{l}\text { Cognitive } \\
\text { Language }\end{array}$ & 112.8 & 16.4 & 80.0 & 145.0 \\
\begin{tabular}{l} 
Motor \\
\hline
\end{tabular} & 102.4 & 13.0 & 74.0 & 144.0 \\
& 111.8 & 14.4 & 73.0 & 154.0 \\
\hline
\end{tabular}

between 1981 and 1983 were $48 \mu \mathrm{g} / \mathrm{l}$, whereas in 1997-1999, it was $33 \mu \mathrm{g} / \mathrm{l}$. Further decrease was observed in our study.

The reason for variability in Se intake relates not only to the Se content of the soil, but also to the factors that determine availability of Se to the food chain, including Se speciation, soil $\mathrm{pH}$, and organic-matter content, and the presence of iron that can complex with Se (30).

Correlation between Se status and maternal BMI was very low $(r=0.05)$, which indicates that Se status does not necessarily reflect the overall nutritional status. It is worth to mention that in our cohort about $20 \%$ of the women consumed multiple micronutrient capsules (with Se as one of their components) but this did not influence Se status $(r=-0.01)$ or associations with child development (1-y-old children: cognitive: $P=0.8$, language and motor: $P=0.6 ; 2$-y-old children: all abilities: $P=0.9$ ). A similar observation has been reported by Skröder et al. (13).

The prospective study design and assessment of Se levels in each trimester of pregnancy as well as in maternal (at delivery), and in cord blood constitute an important advantage of this study. Additionally, a series of detailed questionnaires (and biomarker measurements) made it possible to assess reliably the confounding variables. Restricting our study population to healthy women allowed us to eliminate additional confounding factors, though we have to consider the possibility that other unmeasured risk factors (e.g., maternal IQ, children's maternal relationship, and home environment) produced associations between the exposures of interest and child neurodevelopment. Finally, in the current analysis, we assessed multiple aspects of child neurodevelopment by a well-standardized and widely used tool for early and fairly comprehensive measures.

Limitations of the study are also worth noting. We were not able to assess dietary habits of the women to include them in the analysis, and we did not measure internal exposure to other essential and neurotoxic elements. However, in the analysis by Skröder et al., the models were additionally adjusted for essential ( $\mathrm{Zn}, \mathrm{Mn}, \mathrm{I}$ ) and neurotoxic elements (As, $\mathrm{Cd}, \mathrm{Pb}$ ) and the impact of Se on child psychomotor development was still significant. This indicates that the association with Se was not just a proxy for intake of other micronutrients capable of affecting child development (13). To what extent Se may protect against toxic exposures remains to be evaluated based on REPRO_PL. Although we did not formally correct for multiple comparisons, the associations between Se levels and child development were consistent across the regression models and with the results of previous studies on the topic, thus supporting the evidence of an actual Se effect independent of the covariates.

Table 3. Pearson correlation between the levels of selenium in each trimester of pregnancy, at delivery, and in cord blood

\begin{tabular}{|c|c|c|c|c|c|}
\hline Se levels & $\begin{array}{c}\mathrm{Se} \\
\text { (first trimester) }\end{array}$ & $\begin{array}{c}\mathrm{Se} \\
\text { (second trimester) }\end{array}$ & $\begin{array}{c}\mathrm{Se} \\
\text { (third trimester) }\end{array}$ & $\begin{array}{c}\text { Se (maternal } \\
\text { blood at delivery) }\end{array}$ & $\begin{array}{c}\text { Se } \\
\text { (cord blood) }\end{array}$ \\
\hline Se (first trimester) & 1 & & & & \\
\hline Se (third trimester) & 0.4 & 0.5 & 1 & & \\
\hline Se (maternal blood at delivery) & 0.3 & 0.3 & 0.5 & 1 & \\
\hline
\end{tabular}


Table 4. Selenium levels during the first trimester of pregnancy, in maternal blood collected at delivery, in cord blood and child psychomotor development

\begin{tabular}{|c|c|c|c|c|c|c|}
\hline \multirow{2}{*}{$\begin{array}{l}\text { Selenium level in different } \\
\text { pregnancy periods }\end{array}$} & \multicolumn{3}{|c|}{ 1-y-old children $\beta$ (95\% Cl) } & \multicolumn{3}{|c|}{ 2-y-old children $\beta$ (95\% Cl) } \\
\hline & Cognitive & Language & Motor & Cognitive & Language & Motor \\
\hline \multicolumn{7}{|l|}{ Model 1} \\
\hline Se (first trimester) & $0.01(-0.1$ to 0.1$)$ & $0.04(-0.07$ to 0.2$)$ & $0.2(0.1 \text { to } 0.4)^{* * *}$ & $0.2(0.02 \text { to } 0.4)^{*}$ & $0.2(-0.001 \text { to } 0.3)^{* * *}$ & $0.2(0.003 \text { to } 0.3)^{*}$ \\
\hline $\begin{array}{l}\text { Se (maternal blood at } \\
\text { delivery) }\end{array}$ & $-0.07(-0.2$ to 0.03$)$ & $-0.1(-0.2$ to 0.001$)$ & $0.1(-0.1$ to 0.2$)$ & 0.1 (-0.07 to 0.3$)$ & $0.1(-0.07$ to 0.3$)$ & $0.1(-0.1$ to 0.3$)$ \\
\hline Se (cord blood) & $0.01(-0.1$ to 0.2$)$ & $-0.04(-0.2$ to 0.1$)$ & $0.2(-0.02$ to 0.4$)$ & 0.1 (-0.1 to 0.3$)$ & $0.3(0.05 \text { to } 0.5)^{*}$ & $0.1(-0.2$ to 0.3$)$ \\
\hline \multicolumn{7}{|l|}{ Model 2} \\
\hline Se (first trimester) & $0.04(-0.1$ to 0.1$)$ & $0.04(-0.1$ to 0.1$)$ & $0.2(0.1 \text { to } 0.4)^{*}$ & $0.2(-0.003 \text { to } 0.4)^{* * *}$ & $0.2(0.02 \text { to } 0.4)^{*}$ & $0.2(-0.02$ to 0.4$)$ \\
\hline $\begin{array}{l}\text { Se (maternal blood at } \\
\text { delivery) }\end{array}$ & $-0.05(-0.2$ to 0.1$)$ & $-0.1(-0.2$ to 0.03$)$ & $0.1(-0.1$ to 0.2$)$ & $0.1(-0.1$ to 0.3$)$ & $0.1(-0.1$ to 0.3$)$ & $0.1(-0.1$ to 0.3$)$ \\
\hline Se (cord blood) & $0.003(-0.2$ to 0.2$)$ & $-0.1(-0.2$ to 0.1$)$ & $0.2(-0.02$ to 0.4$)$ & $0.1(-0.2$ to 0.4$)$ & $0.2(-0.1$ to 0.4$)$ & $0.1(-0.2$ to 0.4$)$ \\
\hline \multicolumn{7}{|c|}{$\begin{array}{l}\text { Model } 1 \text { is adjusted for the examiner; for 1-y-old assessments: Se (first trimester): } N=373 \text {, Se (maternal blood at delivery): } N=301 \text {, Se (cord blood): } N=301 \text {; for 2-y-old assessments: } \\
\text { Se (first trimester): } N=231 \text {, Se (maternal blood at delivery): } N=231 \text {, Se (cord blood): } N=231 \text {. Model } 2 \text { is adjusted for the examiner, mother age, mother education, child gender, } \\
\text { marital status, and cotinine level; for } 1 \text {-y-old assessments: Se (first trimester): } N=368, \text { Se (maternal blood at delivery): } N=278 \text {, Se (cord blood): } N=278 \text {; for } 2 \text {-y-old assessments: } \\
\text { Se (first trimester): } N=191 \text {, Se (maternal blood at delivery): } N=158, \text { Se (cord blood): } N=157 \text {. } \\
\text { B, beta coefficient; Cl, confidence interval. } \\
{ }^{*} P<0.05 ;{ }^{* * P} P=0.001 ;{ }^{* * * P} P=0.05 \text {. }\end{array}$} \\
\hline
\end{tabular}

\section{Conclusion}

Prenatal selenium status was associated with child psychomotor abilities within the first years of life. Further epidemiological and preclinical studies are needed to confirm the association and elucidate the mechanisms underlying these effects. Taking into account the results obtained in the current study and the existing knowledge, nutritional status of women during pregnancy must be carefully monitored to prevent nutritional unbalance and deficiency of important micronutrients.

\section{METHODS}

\section{Study Design and Population}

The mother-child pairs included in the present study constitute a part of Polish Mother and Child Cohort (REPRO_PL cohort)-a multicenter prospective cohort established in 2007 with the aim to evaluate environmental and lifestyle-related factors contributing to the pregnancy outcomes, children's health, and neurodevelopment (31-35). The detailed description of the cohort methodology has been published elsewhere $(31,32)$. Briefly, the women were recruited into the study if they fulfilled the following criteria: single pregnancy up to $12 \mathrm{wk}$ of gestation, no assisted conception, no pregnancy complications, and no chronic disease as specified in the study protocol. The study subjects were interviewed once in each trimester of pregnancy to collect and update sociodemographic data, medical, and reproductive history as well as information about environmental, occupational, and lifestyle factors. In addition, during each visit and after delivery, biological samples (including saliva, urine, blood, cord blood, and hair) were collected.

The children's health status and neurodevelopment was assessed twice, at 1 and $2 y$ of age.

The current analysis was restricted to 410 children from Lodz and Legnica districts. Among them, 198 children had both assessments (at 1 and $2 y$ of age), 176 were examined only at around the 12th mo, and 36 only at the 24 th mo of age.

The study was approved by the Ethical Committee of the Nofer Institute of Occupational Medicine, Łódź, Poland, and a written consent was obtained from all the study subjects.

\section{Sample Collection and Se Assessment}

Se level was assessed in the blood collected from each woman during the first (8-12 wk of pregnancy), the second (20-24 wk of pregnancy), and the third (30-34 wk of pregnancy) trimesters of pregnancy, and in maternal blood collected at delivery as well as in cord blood. The blood samples were collected using a venoject system free of trace elements with lithium heparin as an anticoagulant. After centrifugation, plasma was collected and frozen at $-20{ }^{\circ} \mathrm{C}$ until the analysis. Plasma Se concentration was determined by the use of the graphite furnace atomic absorption spectrometry according to the method of Nève et al. (36) using Unicam 989 QZ Solaar apparatus. Accuracy of the method was checked using Se reference material (Nycomed, Oslo, Norway). The mean Se level of the reference serum was $78.0 \mu \mathrm{g} / \mathrm{l}$, while of that obtained in our laboratory was $77.4 \pm 5.0 \mu \mathrm{g} / \mathrm{l}$.

\section{Child Neurodevelopment Assessment}

The Bayley Scales of Infant and Toddler Development (the third edition-Bayley-III) was used to assess children's neurodevelopment at around the 13th $( \pm 1.5)$ and 25th $( \pm 2.8)$ mo of age $(32,37)$. Details regarding child psychomotor assessment have been published elsewhere (33-35). Child psychomotor development measured by a raw score/chronologic age was yielded with each subtests, and composite scores for language, motor scales, and composite score equivalent for cognitive scale were generated based on those data.

\section{Covariates}

The evaluated covariates that were identified from the literature were as follows: parental age; parental education; marital status; socioeconomic status; child gender; major pregnancy complications, which appeared after inclusion into the study (including gestational diabetes and gestational hypertension); maternal BMI; type of delivery; gestational age and biometric indicators at birth; breastfeeding; number of siblings; day care attendance; multi micronutrient supplementation; active/passive smoking and alcohol consumption during pregnancy; and child ETS exposure after birth. Sociodemographic data as well as information about alcohol consumption during pregnancy were obtained based on questionnaires. Parental education was expressed as the highest completed formal schooling. Socioeconomic status of the family was measured during pregnancy and after the birth of the child based on the following question: "What is the financial status of your family?" The women who declared that they had sufficient money for current expenses and that it was possible for them to put a substantial sum aside were allocated into the high income category. Those who indicated sufficient money for current expenses, with possibility to put some money aside were allocated into the medium category, and those who declared insufficient money for current expenses were allocated into the low income category. During each prenatal visit scheduled within the study, the women were interviewed by a gynecologist or midwife about the use of vitamins, minerals, other 
dietary supplements, and medications (the name, dose, and time period of their intake were recorded). All of them were checked for selenium content. Prenatal exposure to tobacco constituents was assessed based on the cotinine level in saliva (collected three times during pregnancy) and a child ETS exposure after birth on the cotinine level in urine (collected at the 12th and the 24th mo of age). The biomarker levels were measured using the high-performance liquid chromatography coupled with tandem mass spectrometry/ positive electrospray ionisation and isotope dilution method (38). As the cotinine levels in each trimester of pregnancy were highly correlated (the first with the second trimester: $r=0.8$; the first with the third trimester: $r=0.7$; the second with the third trimester: $r=0.8$, $P<0.001$ ), the samples from between the 8th and the 12th wk of gestation were used as biomarkers of active and passive smoking. The cotinine levels were log transformed. The analysis included the following indicators at birth (measured by a clinical nurse after birth with the standard measurement procedures): child birth weight (in grams), birth length, head and chest circumference (in centimeters). Pregnancy duration was estimated using the date of the last menstrual period or ultrasound if it differed from the last menstrual periodbased estimate by $>2 \mathrm{wk}$.

\section{Statistical Analysis}

Correlation between microelement levels in each trimester of pregnancy, at delivery, and in cord blood was examined by the Pearson linear correlation coefficient.

The linear regression was used to analyze the relationship between Se levels and child psychomotor development. First, an analysis was performed between the potential confounding variables and the Bayley test results. The following confounders (significant in the univariate model at the level of 0.1$)$ for the multivariate model were identified: child gender $(P \leq 0.08)$, parental age $(P \leq 0.03)$, parental education $(P \leq 0.08)$, prenatal ETS exposure $(P \leq 0.05)$, child ETS exposure within the first 2 y of life $(P<0.06)$, and marital status $(P<0.03)$. As some confounders (namely: mother and father's age, mother and father's education, pre and postnatal ETS exposure), were highly correlated, the sensitivity analysis was performed, and only maternal age and education and cotinine level in pregnancy were selected in the final model. The second stage of the analysis focused on the evaluation of the impact of Se level in the first trimester of pregnancy, in maternal blood at delivery, and in cord blood on child psychomotor performance at 1 and 2 y of age. In the first model, a confounding effect of the examiner who administered the test was taken into account. The final model was conducted with adjustment for potential confounders. Taking into account the smaller number of samples collected during the second and the third trimesters of pregnancy, the analysis focused on those trimesters was not performed. The variance inflation factor was computed for any variable in each final model to verify the presence of multicollinearity among explanatory variables. When significantly different from 0 , regression coefficients were reported together with 95\% confidence interval.

Statistical significance was specified as $P<0.05$ (two-sided $P$ values). The analysis was performed using the R software.

\section{STATEMENT OF FINANCIAL SUPPORT}

This work has been funded by the European Community's Seventh Framework Programme (FP7/2007-2013) under grant agreement no. 603946, National Science Centre, Poland, under grant DEC-2014/15/B/NZ7/00998, and National Science Centre under the call JPI HDHL Nutrition and Cognitive Function (2015/17/Z/NZ7/04273).

Disclosure: The authors declare that they have no competing interests.

\section{REFERENCES}

1. Prado EL, Dewey KG. Nutrition and brain development in early life. Nutr Rev 2014;72:267-84.

2. Rayman MP. Selenium and human health. Lancet 2012;379:1256-68.

3. Roman M, Jitaru P, Barbante C. Selenium biochemistry and its role for human health. Metallomics 2014;6:25-54.

4. Holmgren $\mathrm{A}, \mathrm{Lu} \mathrm{J}$. Thioredoxin and thioredoxin reductase: current research with special reference to human disease. Biochem Biophys Res Commun 2010;396:120-4.
5. European Food Safety Authority. EFSA Panel on Dietetic Products NaAN. Scientific Opinion EFSA Panel on Dietetic Products, Nutrition and Allergies (NDA). EFSA Journal 2014;12:3846.

6. Mensink GB, Fletcher R, Gurinovic M, et al. Mapping low intake of micronutrients across Europe. Br J Nutr 2013;110:755-73.

7. Leung BM, Wiens KP, Kaplan BJ. Does prenatal micronutrient supplementation improve children's mental development? A systematic review. BMC Pregnancy Childbirth 2011;11:12.

8. Li Q, Yan H, Zeng L, et al. Effects of maternal multimicronutrient supplementation on the mental development of infants in rural western China: follow-up evaluation of a double-blind, randomized, controlled trial. Pediatrics 2009;123:e685-92.

9. Tofail F, Persson LA, El Arifeen S, et al. Effects of prenatal food and micronutrient supplementation on infant development: a randomized trial from the Maternal and Infant Nutrition Interventions, Matlab (MINIMat) study. Am J Clin Nutr 2008;87:704-11.

10. Watanabe C, Satoh H. Effects of prolonged selenium deficiency on open field behavior and Morris water maze performance in mice. Pharmacol Biochem Behav 1995;51:747-52.

11. Hong LL, Tian DP, Su M, Shen XN, Gao Y. Effect of selenium deficiency on the F344 inbred line offspring rats' neuro-behavior, ability of learning and memory. Wei Sheng Yan Jiu 2006;35:54-8.

12. Yang X, Yu X, Fu H, Li L, Ren T. Different levels of prenatal zinc and selenium had different effects on neonatal neurobehavioral development. Neurotoxicology 2013;37:35-9.

13. Skröder HM, Hamadani JD, Tofail F, Persson LÅ, Vahter ME, Kippler MJ. Selenium status in pregnancy influences children's cognitive function at 1.5 years of age. Clin Nutr 2015;34:923-30.

14. Polish Mother and Child Cohort Study - REPRO_PL. (http://repropl. com/.)

15. Chen J, Berry MJ. Selenium and selenoproteins in the brain and brain diseases. J Neurochem 2003;86:1-12.

16. Schweizer U, Bräuer AU, Köhrle J, Nitsch R, Savaskan NE. Selenium and brain function: a poorly recognized liaison. Brain Res Brain Res Rev 2004;45:164-78.

17. Ansari MA, Ahmad AS, Ahmad M, et al. Selenium protects cerebral ischemia in rat brain mitochondria. Biol Trace Elem Res 2004;101:73-86.

18. Yousuf S, Atif F, Ahmad M, et al. Selenium plays a modulatory role against cerebral ischemia-induced neuronal damage in rat hippocampus. Brain Res 2007;1147:218-25.

19. Watanabe C, Yin K, Kasanuma Y, Satoh H. In utero exposure to methylmercury and Se deficiency converge on the neurobehavioral outcome in mice. Neurotoxicol Teratol 1999;21:83-8.

20. Dalla Puppa L, Savaskan NE, Bräuer AU, Behne D, Kyriakopoulos A. The role of selenite on microglial migration. Ann NY Acad Sci 2007;1096: 179-83.

21. Steinbrenner H, Sies H. Selenium homeostasis and antioxidant selenoproteins in brain: implications for disorders in the central nervous system. Arch Biochem Biophys 2013;536:152-7.

22. Beckett GJ, MacDougall DA, Nicol F, Arthur R. Inhibition of type I and type II iodothyronine deiodinase activity in rat liver, kidney and brain produced by selenium deficiency. Biochem J 1989;259:887-92.

23. Han XJ, Xiao YM, Ai BM, Hu XX, Wei Q, Hu QS. Effects of organic selenium on lead-induced impairments of spatial learning and memory as well as synaptic structural plasticity in rats. Biol Pharm Bull 2014;37:466-74.

24. Jablonska E, Gromadzinska J, Klos A, et al. Selenium, zinc and copper in the Polish diet. J Food Composition Analysis 2013;31:259-65.

25. Rayman MP. Food-chain selenium and human health: emphasis on intake. Br J Nutr 2008;100:254-68.

26. Fairweather-Tait SJ, Bao Y, Broadley MR, et al. Selenium in human health and disease. Antioxid Redox Signal 2011;14:1337-83.

27. Iranpour R, Zandian A, Mohammadizadeh M, Mohammadzadeh A, Balali-Mood M, Hajiheydari M. Comparison of maternal and umbilical cord blood selenium levels in term and preterm infants. Zhongguo Dang Dai Er Ke Za Zhi 2009;11:513-6.

28. Wells EM, Jarrett JM, Lin YH, et al. Body burdens of mercury, lead, selenium and copper among Baltimore newborns. Environ Res 2011;111: $411-7$. 
29. Wasowicz W, Gromadzinska J, Rydzynski K, Tomczak J. Selenium status of low-selenium area residents: Polish experience. Toxicol Lett 2003;137: 95-101.

30. Johnson CC, Fordyce FM, Rayman MP. Symposium on 'geographical and geological influences on nutrition' factors controlling the distribution of selenium in the environment and their impact on health and nutrition. Proc Nutr Soc 2010;69:119-32.

31. Polańska K, Hanke W, Gromadzińska J, et al. Polish mother and child cohort study-defining the problem, the aim of the study and methodological assumption. Int J Occup Med Environ Health 2009;22:383-91.

32. Polańska K, Hanke W, Jurewicz J, et al. Polish mother and child cohort study (REPRO_PL)-methodology of follow-up of the children. Int J Occup Med Environ Health 2011;24:391-8.

33. Polanska K, Hanke W, Sobala W, et al. Developmental effects of exposures to environmental factors: the Polish Mother and Child Cohort Study. Biomed Res Int 2013;2013:629716.

34. Polanska K, Ligocka D, Sobala W, Hanke W. Phthalate exposure and child development: the Polish Mother and Child Cohort Study. Early Hum Dev 2014;90:477-85.

35. Polańska K, Muszyński P, Sobala W, Dziewirska E, Merecz-Kot D, Hanke W. Maternal lifestyle during pregnancy and child psychomotor development Polish Mother and Child Cohort study. Early Hum Dev 2015;91:317-25.
36. Nève J. Methods in determination of selenium states. J Trace Elem Electrolytes Health Dis 1991;5:1-17.

37. Bayley Scales of Infant and Toddler Development, Bayley-Third Edition. (http://www.pearsonclinical.com/childhood/products/100000123/bayley-scales-of-infant-and-toddler-development-third-edition-bayley-iii. html.)

38. Stragierowicz J, Mikołajewska K, Zawadzka-Stolarz M, Polańska K, Ligocka D. Estimation of cutoff values of cotinine in urine and saliva for pregnant women in Poland. Biomed Res Int 2013;2013:386784.

(1) (2) This work is licensed under a Creative Commons Attribution-NonCommercial-ShareAlike 4.0 International License. The images or other third party material in this article are included in the article's Creative Commons license, unless indicated otherwise in the credit line; if the material is not included under the Creative Commons license, users will need to obtain permission from the license holder to reproduce the material. To view a copy of this license, visit http://creativecommons.org/licenses/by-nc-sa/4.0/ 